\title{
MAKNA NYANYIAN MA'KAARUYEN DALAM KEHIDUPAN MASYARAKAT MINAHASA
}

\author{
Markus Wibowo \\ Institut Agama Kristen Negeri Manado \\ wibowomarkus986@iakn-manado.ac.id \\ Diterima 22 September 2019 \\ Disetujui 26 Oktober 2019
}

\begin{abstract}
This research is a meaning of Ma'kaaruyen; a traditional musical work of art originating from Minahasa. Ma'kaaruyen is assumed to be one of the arts that reflects the life of the Minahasa community. Through a musicalological approach to the analysis of musical elements and the analysis of the texts of the Ma'kaaruyen song, meaning is found that integrates with the values of the life of the Minahasa community. In the musical meaning it is known that Ma'kaaruyen has musical elements that form this song included in the category of melancholy singing, so that with lyrics or without lyrics this song is a melancholy song that is able to influence the soul. Ma'kaaruyen's extramusical meanings of the musical elements refer to the nature and character of traditional Minahasa community life, including: rhythm, melody, intervals, harmony, texture, and song form. The elements of music in Ma'kaaruyen are a reflection of the character and nature of traditional Minahasa society, which is associated with simplicity, calmness, gentleness, cooperation (mapalus), and mutual affection. Ma'kaaruyen's extramusical meaning from lyrics is that Ma'kaaruyen is a song that conveys religious messages, advice, affection, and expressions of heart (lamentations and regrets).
\end{abstract}

Keywords: Meaning, Ma'kaaruyen, Minahasa

ABSTRAK

Penelitian ini merupakan sebuah pemaknaan terhadap Ma'kaaruyen; sebuah karya seni musik tradisional yang berasal dari Minahasa. Ma'kaaruyen diasumsikan sebagai salah satu kesenian yang mencerminkan kehidupan masyarakat Minahasa. Melalui pendekatan musikologis dengan analisis unsur-unsur musik dan analisis teks nyanyian Ma'kaaruyen ditemukan makna yang berintegrasi dengan nilai-nilai kehidupan masyarakat Minahasa. Pada makna musikal diketahui bahwa Ma'kaaruyen memiliki unsur-unsur musik yang membentuk nyanyian ini termasuk dalam kategori nyanyian melankolis, sehingga dengan lirik ataupun tanpa lirik nyanyian ini merupakan nyanyian melankolis yang sanggup mempengaruhi jiwa. Makna ekstramusikal Ma'kaaruyen dari unsur-unsur musiknya merujuk kepada sifat dan karakter kehidupan masyarakat Minahasa tradisional, diantaranya adalah: ritme, melodi, interval, harmoni, tekstur, dan bentuk lagu. Elemen-lemen musik pada Ma'kaaruyen merupakan cerminan karakter dan sifat masyarakat tradisional Minahasa, yang berasosiasi kepada kesederhanaan, ketenangan, kelemahlembutan, kerjasama (mapalus), dan sikap saling menyayangi antar sesama. Makna ekstramusikal Ma'kaaruyen dari lirik adalah bahwa Ma'kaaruyen merupakan nyanyian yang menyampaikan pesan religi, nasihat, kasih sayang, dan ungkapan hati (ratapan dan penyesalan).

Kata kunci : Makna, Ma'kaaruyen, Minahasa

\section{PENDAHULUAN}

Masyarakat Minahasa dikenal
gemar bernyanyi, bahkan aktivitas ini
sudah dianggap sebagai budaya. Dalam

${ }^{1}$ Menurut cerita rakyat Minahasa, Lumimuut dan Toar adalah manusia pertama nenek moyang mereka. Keduanya kawin dan menghasilkan keturunan yang sangat banyak dan hidup acara adat maupun gerejawi selalu ada kesempatan untuk menampilkan nyanyian, baik berupa nyanyian solo, vocal group, maupun paduan suara. Etnis Minahasa ${ }^{1}$

berkelompok-kelompok. Ada tiga kelompok yang umum dikenal, yaitu: (1) Makarua - souw , (2) Makatelu - pitu, dan (3) pasiwouwan - telu. Golongan pertama ialah pemuka agama yang 
yang mayoritas Kristiani ini memiliki ribuan kelompok paduan suara yang tersebar di berbagai denominasi (aliran) gereja antara lain: Protestan, Katholik, Pantekosta, Advent, dan lain-lain. Di samping itu, ada juga kelompok paduan suara bentukan instansi, sekolah, perguruan tinggi, kampung atau perorangan sebagai sekedar penyaluran hobi. Bernyanyi secara berkelompok juga dilakukan dalam pertemuan-pertemuan kemasyarakatan, seperti: pertemuan arisan, kerja bakti, rapat, dan lain-lain dan tentunya juga dalam pertemuan kelompok-kelompok doa di rumah-rumah (Perry Rumengan, 2005:188).

Fenomena lain yang serupa dapat dilihat dari berbagai kegiatan seperti: menanam padi, memetik padi, menebang pohon, mapalus (kerja bakti), berburu, acara syukuran naik rumah baru, berdoa memohon bantuan Opo (Tuhan), acara perkawinan, kelahiran, dan kematian. Ada juga acara mengusir hama, memohon hujan turun, membuai anak, dan lain-lain (Inkiriwang-Kalangie, 1985: 16-18).

berfungsi sebagai walian dan tonaas, golongan kedua ialah pemuka dalam bidang pemerintahan dan panglima perang, dan golongan ketiga ialah petani, pemburu dan nelayan.

2 Musik Karambangan, yang diyakini berakar dari budaya Barat yang kemudian masuk ke tanah Minahasa, dibawa oleh bangsa Portugis dan Spanyol sekitar tahun 1523 hingga 1606. Orang
Kebiasaan menyanyi ini juga dilakukan saat santai duduk di halaman rumah sambil menikmati indahnya terang bulan. Pada situasi itu teks lagu atau syair dalam nyanyian banyak mengandung nasihat yang bijaksana dari orangtua kepada anak, biasanya nasihat kepada anak perempuan agar berhati-hati dalam menjalani hubungan dengan pria, atau nasihat kepada anak laki-laki agar ketika pergi ke rantau jangan melupakan orangtua dan kampung halaman, sehingga bilamana para tetangga mendengar orang-orang tua sedang bernyanyi mereka akan merasa terharu dan sedih dan tak segan-segan meneteskan air matanya. Kegemaran bernyanyi etnis Minahasa itu juga melahirkan beberapa macam nyanyian khas, antara lain: Maengket, Ma'owey, Marayor, Mahasani, Ma'kaaruyen, dan lain-lain yang sangat memperkaya budaya Minahasa.

Nyanyian Ma'kaaruyen pada awalnya merupakan musik hasil pencampuran antara budaya Minahasa dengan budaya Barat yang dahulu dikenal dengan nama Karambangan. ${ }^{2}$ Lambat laun

Spanyol yang pertama kali mendiami Minahasa adalah para tahanan Portugis yang melarikan diri dari Philipina ke Ternate, kemudian mereka ke tanah Minahasa (F.S. Watuseke, 1968:33). Seiring dengan berjalannya waktu, orang-orang Spanyol tersebut akhirnya kawin dengan orang-orang Minahasa. Keberadaan orang Spanyol pada waktu itu sempat memperkenalkan budaya dan nyanyian-nyanyian Spanyol, salah satunya Charamba, yaitu tarian berpasangan (Suhardjo Parto, 1995: 6). 
istilah Karambangan dikenal oleh masyarakat Minahasa dengan nama Ma'kaaruyen. Oleh sebagian besar orang Minahasa, Ma'kaaruyen dianggap sama dengan Karambangan. Ada juga orang Minahasa yang menyebutnya dengan nama Musik Kobong (musik kebun), atau nyanyian kerja. Kata Ma'kaaruyen sendiri berasal dari beberapa rumpun Bahasa di Minahasa, seperti Arruyen dari Bahasa Tonsea $^{3}$ yang berarti 'saling menyayangi' dan 'saling mengasihi', kata ini terungkap dalam ungkapan sehari-hari “... ma'aruyaruyen sera ... " ; dalam rumpun bahasa Tontemboan kata itu berasal dari kata aruy yang berarti 'keharuan, keindahan, pesona, kekaguman pada sesuatu' (Djery Warokha, 2005: 54).

Ma'kaaruyen diasumsikan sebagai sebuah cerminan kehidupan masyarakat Minahasa, seperti halnya musik tradisi di Nusantara lainnya yang sebagian besar mencerminkan kehidupan masyarakat pemilik tradisi tersebut. Salah satu contohnya adalah tangga nada slendro dan pelog pada gamelan Jawa yang merupakan wujud dari kehidupan masyarakat Jawa dan bentuk sikap dalam bertindak. Contoh lain seperti yang dikatakan oleh Suka Harjana bahwa musik gamelan Bali menunjukkan

3 Suku Minahasa terbagi atas sembilan subsuku: (1) Babontehu, (2) Bantik, (3) Pasan Ratahan, (4) Ponosakan, (5) Tonsea, (6) Tontemboan, (7) Tondano, (8) Tonsawang, dan (9) Tombulu. Di antara sembilan subsuku di atas, yang watak dan sikap masyarakat Bali (Hardjana, 2003: 38). Hal ini juga terjadi pada Ma'kaaruyen yang merupakan gambaran bahwa sebagian besar masyarakat Minahasa hidup berkelompok, hidup selaras, dan mempunyai semangat kerjasama yang tinggi (mapalus). Dengan semangat yang dimilikinya masyarakat Minahasa enggan berpisah dari komunitas dan dari keluarga mereka. Hal-hal tersebut di atas tercermin pada tangga nada dan harmonisasi nyanyian Ma'kaaruyen.

Salah satu ciri nyanyian Ma'kaaruyen adalah sifatnya yang melankolis, bahkan cenderung sedih, sehingga orang yang mendengarkan akan merasa luluh hatinya (Rumengan, 2009; 147). Disebut melankolis karena dilihat dari teks lagunya, nyanyian ini merupakan suatu ratapan, penyesalan, takjub atau terpesona terhadap ciptaan Tuhan, atau terkadang suatu nasihat yang diberikan oleh orangtua kepada anak-anaknya. Selain itu, nyanyian Ma'kaaruyen dibawakan dengan irama yang mendayu-dayu serta menggunakan nada-nada yang terkesan monoton dan diulang-ulang (bergaya repetisi). Gaya dalam bernyanyi inilah yang menimbulkan rasa iba dan sedih kepada pendengarnya, sehingga Ma'kaaruyen disebut sebagai

termasuk subsuku terbesar adalah : Tontemboan, Tonsea, Tombulu, dan Bantik. 
nyanyian yang menyedihkan dan membangkitkan rasa belas kasihan, yang di dalam bahasa lokal disebut dengan istilah dapa sayang. Noldy Wenas dalam penelitiannya mengemukakan bahwa Ma'kaaruyen merupakan musik yang berbeda dengan musik lainnya. Harmoni dalam Ma'kaaruyen bergerak paralel dan menggunakan melodi-melodi yang terkesan monoton (Noldy Wenas, 2008: $31)$.

Dari uraian di atas tampak bahwa nyanyian Ma'kaaruyen terintegrasi sangat kuat dengan kehidupan masyarakat Minahasa. Fenomena ini bagi peneliti menarik untuk diteliti terutama dalam kaitannya dengan makna nyanyian ini dalam kehidupan masyarakat Minahasa.

\section{Landasan Konseptual}

Penelitian ini merupakan kajian tentang mengungkapkanmakna nyanyian Ma'kaaruyen. Sebagaimana yang tercantum pada bagian latar belakang penelitian, yaitu bahwa nyanyian Ma'kaaruyen diasumsikan sebagai "cerminan dari kehidupan masyarakat Minahasa" dan merupakan perwujudandari sifat dan karakteristik masyarakat Minahasa.
Nyanyian

Ma'kaaruyen mengandung dua makna yang merupakan cerminan kehidupan masyarakat Minahasa, yaitu: makna musikaldan makna ekstramusikal. Makna musikal merupakan pemaknaan berdasarkan unsur-unsur musik tanpa merujuk kepada hal-hal yang diluar musik, makna musikal dari sebuah karya itu bersifat intramusikal, artinya hanya menyangkut pola-pola dan hubungan unsur musik yang sudah terbentuk di dalam sebuah karya dan seluruh sifat intrinsik dari proses yang ada di dalam karya tersebut. Makna musikal merupakan makna yang muncul dari dalam diri musik itu sendiri. Makna musikal ini tidak berkaitan dengan hal-hal lain di luar musik. Perry Rumengan mengemukakan bahwa bunyi musikal adalah bunyi yang di dalamnya mengandung ide. Ide musikal dapat berupa kesan, pesan, atmosferatau ungkapan suasana rasa batin tertentu (Rumengan, 2011:24).

Makna musikal dapat diketahui melalui pengamatan unsur-unsur musiknya (melodi, ritme, harmoni, tekstur, lirik, dan bentuk lagu). Sedangkan makna ekstramusikal merupakan makna yang terkandung pada karya yang diasosisasikan kepada hal-hal yangdi luar musik, sehingga ketika Ma'kaaruyen diamati maka seseorang akan mengasosiasikan terhadap hal-hal yang di luar musik.Makna ini ada 
kalanya berkaitan dengan pandangan hidup manusia, sosial, religi, dan lain-lain. Makna ekstramusikalmenurut Slonimsky adalah musik yang dikategorikan dengan istilah musik program. Slonimsky mengartikan bahwa musik program adalah komposisi instrumental yang dimaksudkan untuk menggambarkan sebuah suasana (mood) atau fase emosi tertentu (Slonimsky, 1998:410). Ma'kaaruyen dapat menggambarkan sebuah suasana atau sebuah pandangan hidup masyarakat minahasa. Makna ekstramusikal Ma'kaaruyen dapat ditemukan melalui analisis lirik lagunya. Seperti yang dikemukakan oleh Perry Rumengan bahwa

"Musik tidak mengekspresikan kata-kata dengan tafsirannya yang terbatas, melainkan dalam bahasa kata tafsiran bisa lebih konkret.Bahasa kata bisa disampaikan sedemikian rupa dengaan formulasinya sehingga sebisanya dapat memunculkan interpretasi yang seminimal mungkin. Bahkan dalam status tertentu dapat mencapai interpretasi tunggal, apalagi kalau simbol dan makna dalam bahasa kata yang digunakan sudah disepakati bersama oleh komunitas yang akan menginterpretasikannya" (Rumengan, 2011:25).

Menurut Agawu bahwa ada beberapa langkah yang dilakukan pada saat mengungkapkan makna, diantaranya adalah; denoting, embodying, expressing, representing, dan symbolizing. Menurut Agawu jika ada serangkaian not yang membentuk rangkaian akor sedang bergerak turun, maka ini 'menyimbolkan' sesuatu yang bergerak dari posisi tinggi menuju ke posisi rendah; sedangkan not-not yang sudah ada pada posisi tertentu ia 'menunjukkan' bahwa

not itu memiliki nada standar yang sudah disepakati bersama. Misalnya untuk not ' $A$ ' ia mempunyai frekuensi 440 hertz danini tidak akan berubah, demikian pula untuk not-not lain. Setiap not mempunyai frekuensi masing-masing yang sudah ditetapkan. Dalam sebuah karya , tentu ada yang disebut bentuk, bagian awal, tengah, akhir, tonika, dan lain-lain. Misalnya sebuah karya sonata dari Beethoven. Untuk menunjukkan hal ini maka Beethoven harus merepresentasikan sesuatu yang mencerminkan sebuah karya sonata, atau jika sebuah karya diakhiri oleh tonika maka tentunya ada akor-akor tertentu yang menunjukkan bahwa ada gerakan (progresi) menuju akor tonika. Istilah "ekspresi" atau mengungkapkan menurut kamus biasanya diartikan dengan menyatakan, menunjukkan, atau bermanifestasi dalam sikap, perasaan, ciri-ciri tertentu, atau menunjukkan kekuatan. Ekspresi musikini bisa disamakan seperti ekspresi wajah. 
Dalam Klasik, ekspresi dinyatakan dalam tanda-tanda dinamika seperti:crescendo, decrescendo, forte, piano, dan lain-lain.

Dengan cara denoting dimaksudkan sebagai suatu cara untuk menunjukkan karakter yang dimiliki oleh rangkaian nadanada musik tersebut, yang bisa memberikan kesan "stabil" atau "tidak stabil", sehingga menenangkan atau menggelisahkan.

Selanjutnya, embodying bagi Agawu ialah pengalaman musikal seseorang yang berkaitan dengan styletertentu, dan ini sangat dikenali oleh pendengarnya. Representing menyatakan bahwa sebuah karya merepresentasikan sebuah bentuk lagu tertentu, misalnya lagu dua bagian, tiga bagian, bentuk rondo, bentuk sonatadan sebagainya. yang bisa dikenali dari pembagian frase-frase nya. Yang dimaksudkan dengan expressing dalam oleh Agawu ialah "extroversive semiosis”, yaitu hubungan antara nuansa musikal dengan hal-hal yang bersifat ekstramusikal (di luar musikitu sendiri), misalnya bunyi seperti burung jenis tertentu.

Selanjutnya symbolizing yaitu gerakan nada-nada musikal, termasuk di dalamnya interval-interval nada, menyimbolkan sesuatu yang bisa mengisyaratkan bahwa sebuah karya mengesankan "canggih", "biasa”, "tenang”, "agresif", dan lain-lain (Robinson, 1997: 28-32).

Pada pengungkapanmakna musikalini pendapat Agawu menjadi konsep dalam melakukan analisisunsur-unsurmusik Ma'karuyen. Dari kelima langkah yang dikemukakan oleh Agawu empat diantaranya adalah analisis untuk mengungkapkan makna musikal (denoting, embodying, representing, dan symbolizing). Sedangkan pada bagian expressing Agawu menghubungkan musik dengan hal-hal yang di luar musik, inilah yang merupakan makna ekstramusikal. Makna ekstramusikal dari nyanyian Ma'kaaruyen terdapat dalam hubungan antara karya tersebut dengan fenomena yang dirujuknya. Dengan kata lain dalam makna ekstramusikal nyanyian Ma'kaaruyen memiliki makna yang lebih dari sekedar kata-kata, tetapi merujuk kepada suatu nilai-nilai kehidupan masyarakat Minahasa, di antaranya adalah: nilai-nilai religi, sosial, kasih sayang, dan ratapan/peyesalan.

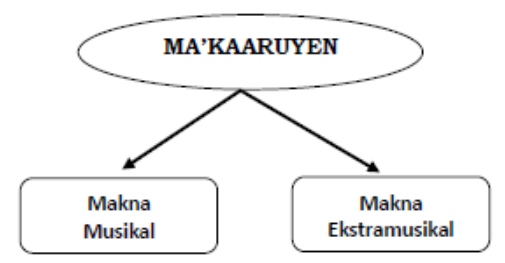

Gambar 1. Makna Ma'kaaruyen 
Berdarkan uraian di atas maka alur konseptual dalam rangka pemaknaan nyanyian Ma'kaaruyen adalah seperti yang digambarkan oleh bagan alur di bawah ini.

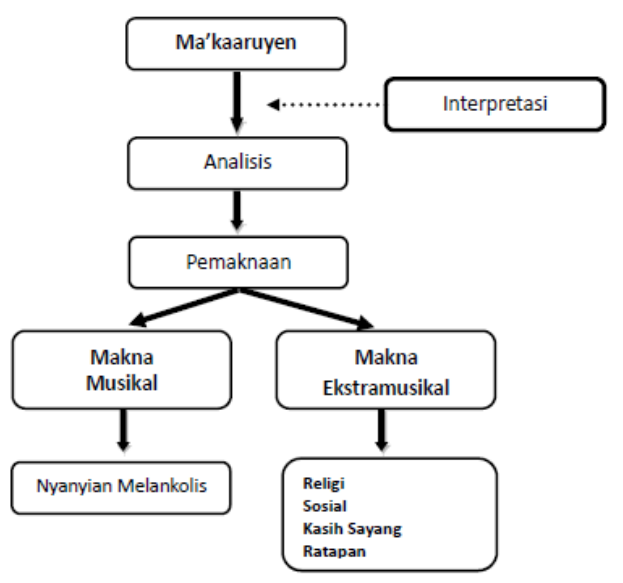

Gambar 2. Alur Landasan Konseptual

\section{Metode}

Penelitian ini menggunakan penelitian metode kualitatif yang dilakukan dengan cara pendekatan musikologis. Pendekatan musikologis diartikan sebagai upaya untuk mengungkapkan aspek-aspek musik baik intramusikal maupun ekstramusikalnya melalui analisis nadanada melodi, harmoni, irama, dan liriknya. Seperti yang dikemukakan oleh Otto Kinkeldey dalam buku Harvard Dictionary of Musictulisan Willi Apel mengatakan, bahwa

...musikologi mencakup seluruh pengetahuantentang musik yang sistematik sebagai akibat dari aplikasi satu metode penelitian ilmiah atau spekulasi filosofi dan sistematika rasional terhadap fakta-fakta, proses dan perkembangan seni musik, hubungan manusia secara umum bahkan dengan dunia binatang (Wili Apel, 1965:473).

Ha Lang dan L. Harap dalam Harvard Dictionary of Music (1965) tulisan Willi Apel berpendapat, bahwa musikologi menyatukan dalam domain-domainnya seluruh ilmu yang menyangkut produksi, rupa, dan aplikasi dari fenomena fisik bunyi.

\section{Deskripsi Nyanyian Ma'kaaruyen}

$$
\text { Musik dalam nyanyian }
$$

Ma'kaaruyen terdiri atas melodi (yang dinyanyikan), harmoni dan ritme (yang dimainkan oleh gitar sebagai musik instrumen). Kadang-kadang instrumen lebih dari satu, misalnya ditambahkan ukulele. Penyanyi Ma'kaaruyen bisa bernyanyi secara solo sambil bermain gitar, atau bernyanyi ansambel ( 2 atau 3 orang). Intro dan interlude biasanya diisi dengan suara siul yang dibunyikan secara tremolo.

$$
\text { Pola-pola musik disesuaikan }
$$
dengan suasana melodi yang dibangun dan terkesan luwes; frase-frase melodi dimainkan secara improvisasi dan mengalir begitu saja. Penalaan dawai gitar untuk lagu Ma'kaaruyen kadang-kadang dilakukan dengan pola tertentu mengikuti nada dasar 
yang digunakan. Misalnya, bila nada dasar nyanyian adalah $\mathrm{C}$ mayor, maka dawai no. 4 diturunkan menjadi nada "d"; dawai no. 5, menjadi "a"; dawai no. 6 dinaikkan menjadi “f” (Wenas, 2008:49). Penalaan ini dimaksudkan agar penyanyi berada pada zona suara nyaman sehingga bisa menyanyi dengan leluasa tanpa merasa kuatir akan nada yang terlalu rendah atau tinggi.

Teknik menyanyikan nyanyian Ma'kaaruyen berbeda dengan umumnya yang dikenal pada musik Barat. Penyanyi dalam melantunkan lagu sering menambahkan not-not pendek yang berfungsi sebagai cengkok, memproduksi nada dari leher (glotich) tetapi tidak kedengaran pecah yang disebut peka'zani kero'an , menggelombangkan suara (vibrato) yang disebut peka'zani ma 'go 'go', sengaja mengucapkan kata-kata syair dengan tidak begitu jelas, dalam musik konvensional Barat disebut morendo ${ }^{4}$ dan memproduksi suara dengan teknik portamento ${ }^{5}$, yang dalam bahasa Manado disebut "dapa sayang" dan dalam bahasa Minahasa disebut Ma'kaaruyen, agar lantunan nada kedengaran melankolis dan memelas. Terkadang menggunakan gaya menyanyi seperti orang yang menangis terisak-isak dalam istilah

${ }^{4}$ Morendo, terjadi decrescendopada kadens; cara main yang semakin lemah, volume suara dan temponya semakin lambat (Banoe, 2003:281).
Minahasa disebut Peka'zani paáyuz pa'elle, menurut Rumengan teknik tersebut yang membuat suasana Ma'kaaruyen menjadi melankolis (Rumengan, 2011:336340). Seluruh teknik ini mencerminkan bahwa orang Minahasa bermusik dengan sangat bebas, lahir dari luapan lubuk hati walaupun tidak mengabaikan begitu saja norma-norma dalam musik.

Menyusun sebuah melodi didasari pada sebuah tangga nada (atau yang lazim disebut "modus"). Ada dua modus dalam musik konvensional Barat, yaitu mayor yang terdiri atas: $d o-r e-m i-f a-s o l-l a$ - si-do' dan minor yang terdiri atas: $l a-$ $s i-d o-r e-m i-f a-s o l-l a$. Akan tetapi di Minahasa, modus yang paling populer, di samping modus-modus lain, adalah modus dengan urutan: $m i^{\prime}-r e^{\prime}-d o^{\prime}-s i-l a-s o l$ - $f a-m i$, sebab tangga nada ini dirasakan oleh masyarakat Minahasa bisa menyatu dengan jiwanya (Rumengan, 2011:315). Telah diuraikan di atas bahwa musik masyarakat Minahasa sangat dipengaruhi oleh bangsa Barat, khususnya Portugis dan Spanyol. Hal ini tampak dari pengaruh modus Phrygian (dengan urutan $\mathrm{mi}-\mathrm{fa}-$ sol -la - si - do - re - mi') yang menjadi dasar musik tradisional flamenco dari Spanyol (Sema, 2009:7). Nuansa

${ }^{5}$ Portamento, penggelinciran nada; teknik permainan musik dengan cara menggelincirkannada ke nada lainnya; dalam vokal disebut penggelinciran suara (Banoe, 2003:341). 
melankolis yang terbangun dari modus sangat cocok dengan spirit masyarakat Minahasa yang tertuang dalam nyanyiannyanyian Ma'kaaruyen. Dengan memahami konsep modus yang digunakan, maka dapat dikatakan bahwa musik Minahasa sesungguhnya merupakan musik simbolis, maksudnya simbol dari keadaan alam, pandangan hidup serta hakikathakikat yang terjadi di alam semesta dan seluruh isinya. Sedangkan konsep keindahan musikal bagi orang Minahasa lebih didasarkan pada prinsip keselarasan, baik yang terjadi dalam diri-sendiri (antara pikiran-perasaan dan kemauan), maupun antara diri sendiri dengan alam (Rumengan, 2011:414).

Instrumen, khususnya yang berjenis petik seperti gitar, ukulele, sangat terintegrasi kuat dalam nyanyian Ma'kaaruyen. Gerakan akor-akor gitar pada umumnya sederhana dan mengikuti kelaziman aturan harmoni konvensional dari musik Barat. Walaupun demikian, aturan harmoni bukanlah yang terutama karena yang terpenting adalah keselarasan akor dengan melodi pokok. Gitar dimainkan dengan cara di-genjreng (strumming) untuk mengiringi alunan melodi yang mendayu-dayu; selain itu, dipakai juga teknik petik (arpeggio) sebagaimana yang lazim digunakan oleh pemain gitar Portugis dan Spanyol atau kombinasi keduanya. Dalam bermain dengan teknik petik, pemain gitar Ma'kaaruyen sangat dipengaruhi oleh permainan gitar gaya Spanyol, yaitu ibu jari memetik suara-suara bas (dawai 4, 5, dan 6) sementara jari telunjuk, tengah dan manis memainkan suara-suara tinggi (dawai 3, 2, dan 1). Fungsi gitar benar-benar sebagai harmoni, artinya ia tidak pernah lebih menonjol daripada melodi utama yang dinyanyikan, walaupun kadang-kadang disisipkan frase-frase pendek sebagai isian tempat-tempat kosong (filler) untuk membuat harmoni lebih "hidup".

Bentuk nyanyian Ma'kaaruyen biasanya dua bagian $\left(\mathrm{A}-\mathrm{A}^{\prime}\right)$, tiga bagian $\left(A-B-A^{\prime}\right)$, bahkan ada beberapa lagu juga yang memiliki empat bentuk ( $\mathrm{A}-\mathrm{B}$ $\left.A^{\prime}-C\right)$ sehingga terkesan tidak beraturan. Secara umum nyanyian Ma'kaaruyen memiliki urut-urutan dalam pertunjukannya, yaitu :

\section{Intro}

Petikan gitar memainkan empat birama melodi lagu yang akan dinyanyikan. Terkadang melodi untuk intro hampir sama dengan melodi dari bagian lagu, namun ada kalanya intro merupakan melodi yang tidak menunjukkan melodi lagu yang akan dinyanyikan (Improvisasi dari pemain musik). 
2. Pada lagu yang memiliki dua bagian (A - A') maka bait pertama (A) dinyanyikan setelah intro, kemudian dilanjutkan kembali bait kedua (A'). Melodi nyanyian biasanya dinyanyikan oleh dua orang secara duet, bisa dua orang perempuan, atau laki-laki dan perempuan berpasangan. Melodi utama diikuti oleh medoli harmoni, biasanya nada terts-nya, sementara itu melodi kedua selalu mengikuti pergerakan melodi utama secara paralel. Setelah bagian A dan A' dinyanyikan kemudian ada interlude biasanya diisi berupa suara siul (ba floit) yang dibunyikan secara tremolo. Suara siul tersebut menyanyikan satu bagian lagu atau bahkan dua bagian seperti yang dinyanyikan oleh penyanyi. Setelah itu dilanjutkan lagi berupa pengulangan kembali dari bagian A ke bagian A', setelah itu ending.

3. Ending, bagian ini merupakan akhir dari sebuah lagu Ma'kaaruyen. Ending ini biasanya dilakukan oleh pemusik dengan memainkan melodi seperti pada intro sebanyak empat birama.

Penyajian nyanyian Ma'kaaruyen seperti urutan-urutan di atas berlaku pada nyanyian Ma'kaaruyen yang lain. Pada nyanyian yang memiliki bentuk tiga bagian bahkan empat bagian, pada saat pengulangannya terjadi seperti pada lagu dua bagian. Hal ini berbeda dengan lagulagu dari musik Barat atau musik Pop dari daerah lain yang terkadang pada urutannya setelah interlude maka menyanyikan bagian reff atau bagian berikutnya dengan alasan estetika. Dalam nyanyian Ma'kaaruyen pengulangan lagu setelah interlude dilakukan seperti menyanyikan lagu dari awal tanpa memenggal bagian lagu. Beberapa orang Minahasa memberi keterangan bahwa nyanyian Ma'kaaruyen agak monoton dan sedikit membosankan, seperti pengalaman Hangky Turangan (warga Tompaso Baru, Minahasa Selatan) dan Wens Rumenagan (warga Kawangkoan, Minahasa) ketika diminta untuk memberi tanggapan terhadap nyanyian Ma'kaaruyen yang diperdengarkan melalui media audio. Bagi beberapa orang menganggap nyanyian Ma'kaaruyen tidak memiliki pengaruh apapun dalam hidupnya, bahkan menilai secara negatif bahwa musik itu musik yang tidak memiliki estetika. Mungkin karena karakter bentuk lagu serta motif yang sederhana sehingga nyanyian Ma'kaaruyen terkesan monoton dan membosankan.

\section{Analisis Ma'kaaruyen Menurut Teori}

\section{Kofi V. Agawu}

Dalam bukunya Playing with Signs: A Semiotic Interpretation of Classic Music, Kofi V. Agawu mempresentasikan analisis semiotika terhadap repertoar yang lazim dimainkan berdasarkan topik musiknya. Semiotika berasal dari bahasa Yunani 
semeion yang berarti "tanda" atau sign dalam bahasa Inggris. Semitotika adalah ilmu yang mempelajari sistem tanda yang menjadi segala bentuk komunikasi yang mempunyai makna, antara lain: kata (bahasa), ekspresi wajah, isyarat tubuh, film, dan karya sastra yang mencangkup musik maupun hasil kebudayaan dari manusia itu sendiri. Tanpa sistem tanda seseorang tidak akan dapat berkomunikasi satu sama lain.

Sebuah lagu yang berjudul "Nimuntep Suraro" akan menjadi contoh dalam analisis lagu Ma'kaaruyen berdasarkan teori Agawu. Adapun penjelasannya adalah sebagai berikut :

\begin{tabular}{|l|l|lr|}
\hline \multicolumn{3}{|c|}{ Judul lagu: Nimuntep Suraro } \\
\hline No & Identifikasi & \multicolumn{2}{|c|}{ Keterangan } \\
\hline & & & \\
\hline
\end{tabular}

\begin{tabular}{|c|c|c|}
\hline & & $\begin{array}{l}\text { sinkop yang cukup } \\
\text { dominan, } \\
\text { menggunanakan } \\
\text { grace note (not kecil } \\
\text { dalam lingkaran) } \\
\text { yang berfungsi } \\
\text { sebagai nada hias dan } \\
\text { cengkok. Gerakan } \\
\text { nada-nada melodi } \\
\text { masih terkesan wajar, } \\
\text { banyak melangkah } \\
\text { dansedikit melompat, } \\
\text { terkesan sebagai } \\
\text { musik balada pop. }\end{array}$ \\
\hline 2. & Denoting & $\begin{array}{l}\text { Pemberhentian pada } \\
\text { nada } \\
\text { menunjukkan } \\
\text { ketidakstabilan. }\end{array}$ \\
\hline 3. & $\begin{array}{l}\text { Representin } \\
g\end{array}$ & $\begin{array}{l}\text { Lagu ini terdiri atas } \\
\text { satu bagian saja (A). } \\
\text { Motif dari birama } 1- \\
9 \text { diulang persis } \\
\text { dengan sedikit variasi } \\
\text { pada birama } 10-18 .\end{array}$ \\
\hline 4. & Expressing & $\begin{array}{l}\text { Ekspresi nyanyian ini } \\
\text { tercermin pada arti } \\
\text { kata-kata syairnya } \\
\text { yang menyatakan } \\
\text { keinginan seorang }\end{array}$ \\
\hline
\end{tabular}




\begin{tabular}{|l|l|l|}
\hline 5. & Embodying & $\begin{array}{l}\text { pemuda yang ingin } \\
\text { menjadi tentara. } \\
\text { Judul "Nimuntep } \\
\text { Suraro" artinya } \\
\text { 'masuk tentara'. } \\
\text { Style balada, yang } \\
\text { tampak pada ciri } \\
\text { gerakan melodinya } \\
\text { yang mengalir dan } \\
\text { easy listening. }\end{array}$ \\
\hline
\end{tabular}

Nyanyian Ma'kaaruyen dibentuk dari unsur-unsur musik yang memiliki pola yang membentuk satu nuansa yang cenderung tenang, sedikit kurang stabil (nada akhir bukan pada tonika), motif yang sederhana dan adanya pengulangan yang terkesan monoton, harmoni sederhana, adanya grace noteyang membuat cengkokan khas Minahasa yang cenderung melankolis.

Dari uraian di atas maka dapat diungkapkan bahwa ditinjau dari unsurunsur musiknya nyanyian Ma'kaaruyen pada umumnya memiliki ciri-ciri sebagai berikut :

1. Melodi Ma'kaaruyen didasari oleh modus atau tangga nada tertentu. Menurut Yudkin bahwa modusdi dalam musik itu bagaikan warna di dalam lukisan. Modus memberikan kekayaan dan variasi dalam musik (Yudkin, 1999:84). Gerakan melodi umumnya sedikit melompat dan banyak melangkah, baik naik maupun turun, terkesan tidak terjal dan mulus. Gerakan nada-nada seperti ini secara psikologis memberi rasa tenang, lembut, dan teduh. Terkadang juga menggunakan grace note (not hias yang ditulis lebih kecil yang tak diperhitungkan nilainya) untuk menunjukkan cengkok khas. Pada contoh lagu Nimuntep Suraro (Terlampir) dapat dilihat beberapa cengkok yang menjadi ciri khas nyanyian Ma'kaaruyen. Melodi dalam nyanyian Ma'kaaruyen menggunakan nada-nada yang sederhana, maksudnya adalah dalam penggunaan interval-interval nada jarang sekali menggunakan nada-nada yang berjarak jauh atau istilahnya nada yang melompat, namun lebih cenderung menggunakan nada-nada yang intervalnya dekat atau melangkah. Melodi demikian mengesankan nyanyian Ma'kaaruyen memiliki nuansa yang tenang dan lembut, dan teduh.

2. Interval yang digunakan pada lagu Ma'kaaruyen pada umumnya pendek, lompatan terts sering dipakai (misalnya pada lagu Nimuntep Suraro). Lompatan agakjauh, misalnya kwart sempurna. Interval yang pendek-pendek menyebabkan lagu lebih mudah dinyanyikan dan ini memberikan kesan tenang. Nyanyian 
Ma'kaaruyen terdengar lebih tenang dan tidak bertele-tele. Ritme lagu Ma 'kaaruyen pada dasarnya sederhana dan tidak rumit, sehingga mudah dinyanyikan oleh awam sekalipun dan mudah diikuti oleh pendengarnya. Pola-pola ritmenya terdiri atas kombinasi dari nilai not 1/8, 1/4, 1/2 hingga 1 tone; tidak ada kombinasi not-not 1/16-an yang kompleks. Aksen-aksennya sesuai dengan meter (sukat)dan sedikit terjadi sinkop. Ritme pada Ma'kaaruyen yang tidak kompleks ini menyebabkan alur melodi Ma'kaaruyen mulus dan mudah diikuti. Nada-nada nyanyian Ma'kaaruyen pada umumnya menggunakan nada-nada yang panjang, kemudian memiliki tempo yang tidak terlalu cepat dan tidak terlalu lambat. Pada aksen-aksen tertentu menggunakan cengkok dan lebih kepada penggunaan legato. Kondisi ritme yang demikian mengesankan nyanyian Ma'kaaruyen membentuk nuansa yang mengalir tidak tergesa-gesa.

3. Harmoni lagu Ma'kaaruyen sederhana, dibangun oleh trinada-trinada dasar, tidak ada akor berlapis (mis.: M7, m7, M9,dan lain-lain.). Harmoni umumnya tetap mengikuti aturan harmoni konvensional musik Barat dan tidak dijumpai modulasi di dalamnya. Gerakan harmoni yang demikian mengesankan lagu tidak bertele-tele dan tidak membuat gelisah, karena arahnya memang jelas. Melodi biasanya dinyanyikan oleh dua orang, satu orang menyanyikan melodi utama dan satu orang lagi menyanyikan melodi kedua sebagai harmonisasi. Interval melodi utama dan melodi kedua berjarak satu terts (misalnya melodi utama di nada "do", maka melodi kedua di nada "mi”). Melodi utama dan kedua berjalan sejajar secara parallel. Pada instrument gitar, akor-akor yang digunakan akor-akor sederhana tanpa ada akor yang kombinasi, progresi akor pada umumnya adalah progresi yang tidak rumit, misalnya : akor I - Akor V - Akor IV - Akor I. Ada juga lagu yang menggunakan akor minor, namun progresinya masih termasuk sederhana karena perpindahannya tidak seperti lagu-lagu karya musik Barat yang sangat kompleks akornya.

4. Tekstur nyanyian Ma'kaaruyen pada umumnya homofoni. Hal ini dapat dilihat pada contoh lagu (Dapat dilihat pada lampiran lagu) melodi yang dinyanyikan baik melodi utama dan melodi kedua selalu berjalan beriringan bersama instrument musiknya. Gitar berfungsi sebagai penguat melodi (dengan gerakannya yang paralel mengikuti gerakan melodiuama) di samping memberikan latar belakang harmoni. Tekstur semacam ini memberi kesan "jelas" dan "terang", karena melodi tampak menonjol dan terpisah dengan iringan, dengan demikian melodi mudah dikenali dan dinikmati. 
5. Lirik lagu Ma'kaaruyen sebagian besar mengunakan Bahasa daerah, walaupun ada juga yang menggunakan Bahasa Indonesia dan logat Manado (Melayu Manado). Secara teknis lirik lagu pada umumnya silabis, namun ada juga yang liriknya neumatis. Hal ini disebabkan oleh karena pembawaan lagu (Style) yang mengakibatkan satu suku kata dinyanyikan dengan beberapa not.

6. Bentuk lagu (form) Ma'kaaruyen sederhana dan seperti bentuk lagu populer pada umumnya, yaitu terdiri atas satu bagian atau dua bagian. Pembagiannya simetris. Ini yang membuat bangunan musik Ma'kaaruyen sederhana dan terkesan wajar bagi pendengar. Bentuk musik nyanyian Ma'kaaruyen pada umumnya berbentuk biner, yaitu terdiri atas dua bagian, namun ada juga bentuknya yang terner, yaitu bila komposisi dua bagian tadi mengulangi bagian pertama (atau terdiri atas tiga bagian).

\section{Makna Musikal}

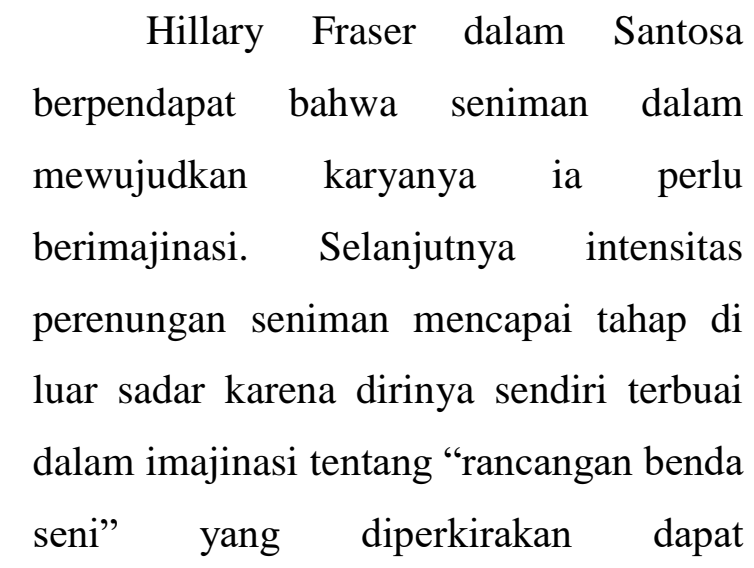

mengungkapkan pandangannya tentang alam, maupun hubungan mereka dengan kekuatan di luar nalar dan supranatural. Sedangkan John Ruskin berpendapat bahwa seniman mengalami proses "pewarnaanimajinasi" yaitu tahap memberikan bentuk akhir terhadap pemikirannya yang spesifik dalam rangka melahirkan benda seni (Santosa, 2014: 104).

Dalam konteks seniman Ma'kaaruyen dalam melahirkan karyanya, ia pun perlu berimajinasi untuk menghasilkan sebuah karya yang mencerminkan kehidupan dan karakter masyarakat Minahasa. Imajinasi seniman tersebut dituangkan secara musikal dalam unsur-unsur musik yang mencakup: melodi, ritme, interval, harmoni, tekstur, dan bentuk musik yang kesemuanya itu terbentuk sebagai satu kesatuan yang utuh.

Karena masyarakat Minahasa mempunyai ciri khas yang membedakannya dari etnis-etnis lain di Indonesia, maka harus ditunjukkan ciri-ciri yang membedakan tersebut dalam sebuah karya musik yang khas pula. Dalam Ma'kaaruyen, setiap unsur musiknya setidaknya mempunyai ciri-ciri yang khas. Hal ini dapat dibandingkan dengan gamelan yang memiliki modus slendro dan pelog dalam gending-gendingnya yang membedakannya dengan karya musik dari 
etnis lain yang menggunakan modus mayor dan minor (misalnya musik dari daerah Indonesia Timur). Selain melodi, unsur-unsur lain seperti ritme, interval, harmoni, tekstur, dan bentuk musik diimajinasikan oleh seniman Ma'kaaruyen sedemikian rupa sehingga karya yang tercipta benar-benar mencerminkan karakter masyarakat Minahasa secara umum.

Makna musikal dari nyanyian Ma'kaaruyen dapat disimpulkan bahwa gagasan yang diekspresikan melalui unsurunsur musik yang membangun mengarahkan kepada suatu kesan nuansa yang cenderung sedih, haru, tenang, dan iba. Dengan kata lain peneliti menganalogikan nuansa yangdibangun oleh Ma'kaaruyen sebagai identitas nyanyian itu adalah nyanyian melankolis.

Berdasarkan uraian di atas dapat dijelaskan bahwa melankolis dalam Ma'kaaruyen merupakan nuansa yang terbentuk oleh unsur musik yang memiliki pola tertentu (baik melodi, ritme, interval, harmoni, form, dan tekstur) sehingga cenderung menghasilkan nuansa yang mempengaruhi emosi manusia untuk merasakan kesedihan. Jenis pergerakan melodi, interval, ritme, dan instrumen musik pada Ma'kaaruyen cenderung memberi kesan yang sedih dan haru.
Adapun pola-pola unsur musiknya adalah sebagai berikut.

1. Melodi Ma'kaaruyen pada umumnya tidak berakhir pada tonika (do) tetapi pada terts (mi).

2. Gerakan melodinya bersifat melangkah (jarang sekali terjadi lompatan nada dengan interval yang tajam).

3. Penggunaan nada-nada yang memiliki nilai not yang panjang, banyak juga nada-nada yang legato.

4. Akor-akor pada instrumen menggunakan akor basic, baik tangga nada mayor maupun minor. Tidak ada akor kompleks sehingga nuansanya tenang dan teduh.

5. Tempo padaumumnya legato atau adagio, sehingga terdengar tidak terlalu cepat maupun terlalu lambat.

\section{Analisis Pembentuk Nuansa Melankolis dalam Nyanyian Ma'kaaruyen}

Nuansa melankolis Ma'kaaruyen dipertegas oleh model dan timbre instrumennya. Instrumen (alat musik) yang digunakan dalam Ma'kaaruyen khususnya yang berjenis petik seperti gitar, ukulele, sangat terintegrasi kuat dalam nyanyian Ma'kaaruyen. (Melankolis dalam hal ini merupakan istilah yang peneliti gunakan untuk menganalogikan nuansa yang ditimbulkan oleh nyayian Ma'kaaruyen) 
Dawai gitar yang dipakai sengaja berbahan kawat tanpa lilitan, sehingga suaranya kedengaran melengking tinggi dan agak pecah (berbeda dengan warna suara dari dawai nyilon yang kedengaran lebih lembut). Bunyi yang "melengking" demikian terkesan seperti "menjerit" atau "merintih".

Gerakan akor-akor gitar pada umumnya sederhana dan mengikuti kelaziman aturan harmoni konvensional dari musik Barat. Walaupun demikian, aturan harmoni bukanlah yang terutama, karena yang terpenting adalah keselarasan akor dengan melodi utama. Gitar dimainkan dengan cara di-genjreng (strumming) untuk mengiringi alunan melodi yang mendayu-dayu; selain itu, dipakai juga teknik petik (arpeggio) sebagaimana yang lazim digunakan oleh pemain gitar Portugis dan Spanyol atau kombinasi keduanya. Dalam bermain dengan teknik petik, pemain gitar Ma'kaaruyensangat dipengaruhi oleh permainan gitar gaya Spanyol, yaitu ibu jari memetik suara-suara bas (dawai 4, 5, dan 6) sementara jari telunjuk, tengah dan manis memainkan suara-suara tinggi (dawai 3, 2, dan 1). Fungsi gitar tidak pernah lebih menonjol daripada melodi utama yang dinyanyikan, walaupun kadang-kadang disisipkan frase-frase pendek sebagai isian tempat-tempat kosong (filler) untuk membuat iringan lebih "hidup".

Berikut ini adalah analisis nyanyian Ma'kaaruyen secara detail lagu yang berjudul "Nimuntep Suraro"

Lagu "Nimuntep Suraro" terkesan melankolis antara lain disebabkan oleh :

1. Gerakan melodi yang tidak berhenti pada tonika "do", tetapi turun dan berhenti pada terts "mi”, yaitu la -sol fa - mi (6-5-4-3).

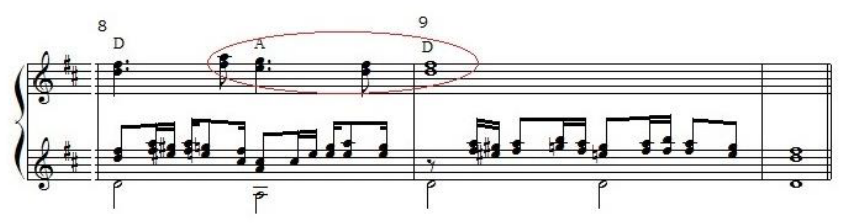

2. Melodi banyak bergerak melangkah, hal ini termasuk perjalanan nada yang membangun nuansa melankolis.

3. Ritme dari melodi tidak kompleks dengan bunyi not relatif panjang.

\section{Makna Ekstramusikal}

Makna ekstramusikal dari sebuah karya musik terdapat dalam hubungan antara karya tersebut dengan fenomena ekstramusikal yang ditunjuknya. Dalam konteks lagu Ma'kaaruyen, hubungan antara unsur-unsur musik dengan lingkungan sekitarnya diketahui dari makna syairnya. Dari syair sebuah lagu Ma'kaaruyen akan diketahui bahwa lagu tersebut sedang berbicara tentang nilai-nilai kehidupan. Hal ini bisa dijelaskan karena 
dalam proses pembuatan syair, muncul kesadaran seniman Ma'kaaruyen terhadap lingkungan di sekitarnya yang membuat mereka berupaya agar pesan dari nyanyian Ma'kaaruyen dapat dimaknai oleh si penikmatnya. Pesan yang akan disampaikan itu tidak berasal dari selera diri seniman itu sendiri, melainkan terutama terinspirasi oleh situasi masyarakat di sekitarnya. Jika tidak demikian, pesan yang akan diungkapkan oleh sang seniman mungkin tidak sinkron dengan harapan masyarakat penikmatnya. Di sinilah seniman Ma'kaaruyenharus cermat dan bisa menangkap fenomena yang sedang terjadi di sekitar. Di antara seniman Ma'kaaruyen itu sendiri, kemampuan seperti ini didapat melalui pengalaman dan perenungan yang didorong oleh adanya motivasi bahwa karya mereka bisa dinikmati oleh para penikmatnya, bukan oleh segelintir penyanyi dan pemusiknya.

\section{a. Ritme}

Ritme adalah unsur paling dasar di dalam musik; dengan ritme, gerak irama musik dapat diikuti. Ma'kaaruyen mempunyai ritme yang stabil dan terkesan tenang. Hal ini karena pembagian meter dan aksen musiknya adalah wajar sebagaimana musik-musik etnis lain di Indonesia. Ini berbeda dengan musik Jazz, misalnya, yang cenderung tidak stabil dan terkesan membuat "gelisah" pendengar. Hal ini oleh karena adanya sinkop (pergeseran aksen) yang menjadi ciri khas dari musik Jazz yang tentu saja berbeda dan terkesan tidak wajar bagi pendengar awam (Pease, 2003:4). Di samping itu, pergerakan ritme yang cenderung konsisten membuat musik Ma'kaaruyen terkesan mengalir. Ini berbeda dengan misalnya musik berirama March yang pola iramanya menggunakan kombinasi not seperempatan bertitik dengan not seperenambelasan yang memberikan kesan langkah tegap dan tergesa-gesa (seperti irama musik militer). Menurut Rumengan bahwa pada dasarnya dalam nyanyian-nyanyian tradisi Minahasa (Ma'zani) tidak ditentukan irama atau ritme yang mengikat (Rumengan, 2009:172). Dalam Ma'kaaruyen ritme muncul sesuai dengan selera dan gaya dari penyanyinya, hal ini disesuaikan dengan emosi dan lirik yang dibawakannya. Dari beberapa contoh tertulis nyanyian Ma'kaaruyen dapat dikategorikan bahwa Ma'kaaruyen memiliki ritme yang sifatnya mengalir, adakalanya menyanyi dengan ritme yang lurus adakalanya menyanyi dengan ritme yang pincang. 16 Ritme seperti yang digunakan dalam Ma'kaaruyen mencerminkan karakter masyarakat Minahasa yang cenderung tenang dan menghindari perselisihan. Seperti yang disampaikan oleh Frans Poli bahwa pada dasarnya masyarakat Minahasa memiliki sifat yang tenang dan menghindari 
perselisihan. Hal ini tercermin dari lagulagu yang iramanya terkesan tidak tergesagesa dan cenderung lembut.

\section{b. Melodi}

Melodi merupakan salah satu unsur yang penting dalam nyanyian, sebab melodi itulah yang kedengaran menonjol danpaling berkesan bagi pendengar(Ammer, 2004:237). Oleh karena itu, peneliti lagu apa pun sangat memperhatikan alur melodi. Melodi yang indah akan dinikmati; sebaliknya, melodi yang buruk akan dilupakan.

\section{Melodi Ma'kaaruyen yang} mengalir terus-menerus merupakan akibat dari kata-kata yang digunakan, sebagai satu dialog, atau ayat-ayat yang saling menguatkan. Bentuk-bentuk pengulangan dimaksudkan agar pendengar bisa lebih memahami dan mengerti isi kata-kata yang disampaikan termasuk untuk menerangkan hal-hal yang bersifat simbolis. Perry Rumengan mengemukakan bahwa lagulagu zaman dahulu, walaupun melodinya tidak terlalu panjang namun syair-syairnya sangat panjang. Menurut Rumengan hal ini sangat dipengaruhi oleh beberapa faktor antara lain : (1) Bahwa lagu-lagu itu sering berisi nasihat. Biasanya melodi tidak mendapat perhatian utama dalam arti tidak dipersiapkan terlebih dahulu. Biasanya peranan melodi sebagai pemberi intensitas dan mempertegas makna dalam menyampaikan nasihat-nasihat itu. Namun perlu juga diingat, bahwa walaupun melodiitu hanya sebagai bantuan, tetapi hal tersebut tidak berarti, bahwa suasana sebagai akibat dari gerakan melodi itu tidak diharapkan. Kehadiran suasana sebagai akibat dari gerakan melodi sangatlah diharapkan hanya kehadiran itu sama sekali tidaklah dirancang lebih dahulu atau dengan kata lain lebih bersifat terjadi, sesuai dengan keadaan dan suasana yang sedang terjadi, dalam hal ini sesuai dengan batin orang yang menyampaikan nasihat itu, termasuk emosi serta isi dari nasihat itu. Suasana yang dipilih itu sangat penting untuk mempengaruhi orang yang sedang dinasihati. (2) Selain alasan tersebut juga ada alasan lain lagi, yaitu karena lagu-lagu Minahasa dulu banyak yang berisi ceritera dan ceritera-ceritera itu sering sangat panjang. (3) Melodi yang dipakai sangat pendek dan biasanya yang diutamakan di situ adalah ceritanya entah cerita yang berupa harapan-harapan, kisah, khayalankhayalan atau kenangan-kenangan (Rumengan, 2007:429-430).

Seniman Ma'kaaruyen sangat mengerti akan hal ini, sehingga ia berusaha menyusun melodi yang bisa diterima oleh masyarakat Minahasa pada umumnya. Melodi itu tidak boleh terlalu asing dan harus mencerminkan watak dari 
masyarakat Minahasa. Melodi Ma'kaaruyen menggunakan modus mayor dan minor sebagaimana yang digunakan olehmusik Barat, alurnya mudah diikuti dan pembagian frasenya tidak terlalu panjang tetapi jelas. Menurut para seniman Ma'kaaruyen di Minahasa (Minahasa Utara dan Minahasa Selatan), dengan ciri melodi seperti itu, seniman Ma'kaaruyen mengimajinasikan watak masyarakat Minahasa yang pada umumnya lembut, ramah dan menerima keberadaaan orang asing.

c. Interval

Interval adalah jarak antara dua nada.Dalam musik, interval menimbulkan suasana tertentu; misalnya, interval terts mayor (do-mi; fa-la) memberikan kesan "maskulin", cerah; interval terts minor (mi -sol; la -do') memberikan kesan “feminim", redup. Selain itu, ada interval konsonan(misalnya terts mayor, terts minor) yang memberikan kesan stabil, nyaman dan tenang yang berlawanan dengan interval disonan(misalnya sekonda mayor [do-re, re -mi]; sekonda minor [mi -fa, si-do']) yang memberikan kesan labil, gelisah dan galau.

Akan tetapi, jika interval itu dibunyikan berurutan ia akan menghasilkan efek yang berbeda-beda. Interval pendek akan berkesan lebih tenang daripada interval panjang. Ini bisa dibandingkan dengan nyanyian-nyanyian doa dari gereja Katholik tradisional (mis. Gregorian) yang bernuansa tenang karena musiknya sebagian besar menggunakan interval pendek-pendek (Benward, 1989:55,56).

Seniman

Ma'kaaruyen

mengimajinasikan karakter masyarakat Minahasa yang menyukai kehidupan tenang dan religius. Dalam praktik menyanyikan Ma'kaaruyen melodi dinyanyikan dengan duet dalam interval terts. Ini menunjukkan bahwa masyarakat Minahasa memiliki sikap bergotongroyong dan cenderung hidup berkelompok bersama sanak saudara. Hal ini seperti yang dikemukakan oleh Perry Rumengan :

“... oleh karena itu mengapa beberapa lagu-lagu tradisi Minahasa dibawakan dengan cara bersama-sama, minimal duet. Hal ini disebabkan bahwa masyarakat Minahasa pada umumnya memiliki rasa tenggang rasa dan saling bekerjasama yang tinggi. Wujud lain adalah adanya mapalus, kumaus, dan lain-lain... "6

\section{d. Harmoni}

Harmoni dalam musik adalah bunyi tiga nada atau lebih secara bersama-sama. Harmoni dalam nyanyian merupakan aspek

\footnotetext{
${ }^{6}$ Rumengan, 2015
} 
yang sangat penting, karena menimbulkan suasana tertentu. Melodi yang indah bila tidak didukung oleh harmoni yang tepat akan mengurangi keindahan nyanyian. Oleh karena itu, seorang arranger harus memahami benar peranan harmoni dalam musik (Apel, 2000:371).

Masyarakat Minahasa adalah masyarakat yang gemar bernyanyi. Mereka sering mengadakan lomba macam-macam paduan suara yang salah satu poin penting penilaiannya adalah harmoni atau keselarasan nada. Di sini tampak bahwa untuk menciptakan harmoni yang indah, di samping susunan nada-nadanya, juga secara teknis ditentukan oleh kekompakan anggota paduan suara tersebut.

Nyanyian Ma'kaaruyen pada umumnya terdiri atas melodi yang dinyanyikan secara duet dan diiringi oleh gitar dan ukulele yang memberikan harmoni sehingga nyanyian itu kedengaran indah. Format seperti ini merupakan imajinasi dari seniman Ma'kaaruyen yang menggambarkan watak masyarakat Minahasa yang kompak dan senang hidup rukun.

\section{e. Tekstur}

Istilah tekstur menunjuk kepada cara merajut materi melodi, ritme dan harmoni di dalam sebuah komposisi. Jenis tekstur yang paling lazim ialah: monofoni, polifoni, homofoni, dan chordal (Benward,1989:165,167).

MasyarakatMinahasa suka dengan nyanyian yang jelas melodinya dan tidak rumit. Hal ini tercermin dari lagu-lagu Minahasa yang dinyanyikan lebih dari satu orang secara bersama-sama. Mereka menghindari pola nyanyian yang bersahutsahutan (tekstur polifoni), dan lebih suka bernyanyi secara serempak bersama-sama dengan iringan instrumen (tekstur homofoni).

Dengan melihat fakta di atas, maka akan tampak kepada kita bahwa seniman Ma'kaaruyen akan selalu menghindari untuk membuat karya lagu yang menggunakan tekstur polifoni, melainkan menggunakan tekstur homofoni. Sang seniman ingin menunjukkan karakter masyarakat Minahasa yang suka hidup bekerjasama (mapalus) dan menghindari persaingan antar anggota masyarakat. Hal ini seperti pendapat Rumengan bahwa harmonisasi serta tekstur lagu-lagu Minahasa mencerminkan kehidupan masyarakat Minahasa yang suka bekerjasama.21

f. Bentuk Lagu

Dalam musik, bentuk lagu merupakan kerangka. Bentuk lagu diartikan sebagai pengelompokan komposisi musik menurut unsur-unsur pembentuknya, 
yaitu:melodi, harmoni dan ritmedan pengolahan unsur-unsur tersebut, yaitu: pengulangan (repetisi), variasi dan kontras. Bentuk lagu yang penting dalam musik Barat: bentuk lagu dua bagian (biner), tiga bagian (terner), sonata form, rondo form, variation form, dan strophic form.(Ammer, 2004:147-148). Sebagaimana lazimnya musik etnis lain di Indonesia, Ma 'kaaruyen menggunakan bentuk lagu yang sederhana dan tidak rumit. Umumnya digunakan bentuk lagu dua bagian $\mathrm{A}-\mathrm{B}$ yang terdiri atas bait dan refrain; selain itu, pembagian frase-frasenya jelas dan seimbang. Ini bisa dibandingkan dengan karya-karya dari zaman Klasik yang mempunyai pembagian frase jelas dan seimbang.

Dengan pembagian frase-frase yang seimbang itu akan tercipta kesan yang nyaman dan wajar bagi pendengarnya. Pola pembagian yang demikian itu menciptakan karya musik yang sederhana dan tidak kompleks, yang lazim dijumpai di banyak lagu populer. Dengan bentuk lagu yang sederhana, seniman Ma'kaaruyen ingin mengimajinasikan masyarakat Minahasa yang suka akan hal-hal yang praktis dan yang tidak berbelt-belit serta menghindari segala macam kerumitan. Mereka ingin segala sesuatu jelas dan tidak ada yang disembunyikan bila ada perselisihan di antara anggota masyarakat.
Masyarakat Minahasa memiliki sifat yang murah hati dan suka menolong, terutama di daerah pedesaan. Adanya unsur kerjasama yang tinggi yang dilampiaskan melalui harmonisasi nyanyian Ma'kaaruyen. Rasa kebersamaan ini merupakan sifat dan karakter, yang akhirnya menjadi tradisi dan budaya orang Minahasa. Hal ini seperti pendapat Rumengan bahwa :

Sifat dan karakter ini tercermin dalam seni mereka. Sebagai contoh, dalam tarian-tarian yang ada di Minahasa tidak dikenal tari tunggal, demikian juga dalam nyanyian tidak ditemukan nyanyian yang dibawakan secara solo (Rumengan, 2011:199).

\section{PENUTUP}

Nyanyian Ma kaaruyen boleh dikatakan sebagai suatu rintihan rasa dengan estetika manusia yang senantiasa menyatu dengan alamnya. Sebagian besar teks lagu nyanyian Ma'kaaruyen merupakan ungkapan pedih karena ditinggal orang terkasih, rasa rindu karena tinggal jauh di rantau, nasihat orangtua kepada anak, rasa kagum kepada alam dan Sang Pencipta. Tidak heran bila nyanyian Ma'kaaruyen selalu bernua nsa melankolis atau sedih'. 
Selain itu, nyanyian Ma'kaaruyen dibawakan dengan irama yang mendayu dayu serta menggunakan nada nada yang terkesan monoton dan diulang ulang (bergaya repetisi). Gaya bernyanyi seperti ini juga berperan membangkitkan rasa iba dan sedih kepada pendengarnya, sehingga Ma kaaruyen disebut sebagai nyanyian yang menyedihkan dan membangkitkan rasa belas kasihan, yang di dalam bahasa lokal disebut dengan istilah dapa sayang Nyanyian Makaaruyen lebih didominasi oleh ungkapan rasa daripada ketaatan pada aturan musik'. Inilah yang menyebabkan nyanyian Ma kaaruyen kedengaran sedikit janggal " terutama bagi orang yang biasa mendengarkan musik Barat. Musiknya terkesan monoton dengan irama mendayu dayu, gerakan akor yang dimainkan oleh gitar, ukulele atau banjo cenderung mengikuti keselarasan " terhadap nada nada melodi menurut perasaan pemainnya. Modus yang digunakan sangat khas dan sangat cocok bagi spirit masyarakat Minahasa. Dalam Dalam memaknai Ma'kaaruyen peneliti mengkategorikan dua macam makna, yaitu (1) makna musikal dan (2) makna ekstramusikal. Makna musikal menyangkut hal hal intramusikal ; sedangkan makna ekstramusikal menyangkut hal hal ekstramusikal. Dalam makna musikal , aspek aspek yang membangun karakter musik Ma kaaruyen yan g antara lain terdiri atas: melodi, interval, ritme, harmoni, bentuk lagu dan tekstur, masing masing secara musikal membentuk pola pola khas tertentu dan bersinergi sedemikian rupa, sehingga terbangun nuansa melankolis ". Sifat melankolis ini benar benar $\mathrm{m}$ enjiwai nyanyian, sehingga Ma'kaaruyen tetap akan kedengaran melankolis, sekalipun seandainya dinyanyikan tanpa syair (dengan bersenandung). Sifat melankolis dalam Ma kaaruyen merupakan perpaduan antara unsur unsur yang terbangun dengan pembawaan (style) dalam membawakan lagu Ma kaaruyen.

Pada makna ekstramusikal, ada kaitan erat antara Ma'kaaruyen dengan masyarakat penciptanya yang tampak dari makna syairnya. Syair nyanyian $\mathrm{Ma}$ kaaruyen berbicara tentang nilai-nilai kehidupan dari masyarakat penciptan ya, karena sebelum nyanyian Ma'kaaruyen tercipta, muncul kesadaran seniman terhadap lingkungan di sekitarnya yang membuat mereka berupaya agar pesan dari nyanyian Ma kaaruyen itu dapat bermakna bagi masyarakat penikmatnya. Pesan yang akan disampaikan itu tidak berasal dari selera diri seniman itu sendiri, melainkan terutama terinspirasi oleh situasi masyarakat di sekitarnya. Jika tidak demikian, pesan yang akan diungkapkan oleh sang seniman mungkin tidak sinkron dengan harapan masyarakat penikmatnya. 


\section{DAFTAR PUSTAKA}

Agawu, V. Kofi. Playing with Signs: A Semiotic Interpretating of Classic Music. New Jersey: Princeton University Press, 1991.

Apel, Willi. Harvard Dictionary of Music (second edition, revised andenlarged). Massachusetts, Cambridge: The Belknap Press of Harvard University Press. 2000

Ammer, Christine.The Facts On File Dictionary of Music. New York: Facts On File. 2004.

Benward, Bruce. Music in Theory and Practice (fourth edition) edition). Dubuqe: Wm. C. Brown Publisher, 1989

Campbell, Michael. Popular Music in America: The Beat Goes On (fourth USA: Schirmer Cengage Learning, 2013

Endraswara, Suwardi. Metode, Teori, Teknik Penelitian Kebudayaan: Ideologi, Epistemologi, dan Aplikasi. Yogyakarta : Pustaka Widyatama, 2006

Hardjana, Suka. Corat coret Musik Kontemporer Dulu dan Kini.Jakarta : Ford Fondation dan Masyarakat Seni Pertunjukan Indonesia, 2003.

Hidayat, Rahmat. Analisis Analisis Semiotika Makna Motivasi Pada Lirik Lagu Laskar Pelangi " Karya Nidji ”. Jurnal Ilmu

Komunikasi Fakultas Ilmu Sosial dan Ilmu Politik, Universitas Mulawarman. Volume 2, Nomor 1, 2014: 243258

Inkiriwang Kalangie, dkk. Upacara Tradisional yang berkaitan dengan peristiwa alam dan kepercayaan daerah Sulawesi Utara. Jakarta : Departemen Pendidikan dan Kebudayaan, 1985.
Khan, Hazrat Inayat. Dimensi Mistik Musik dan Bunyi. Terj. Subagijono dan Fungky Kusnaedy Timur dari buku Themysticism of sound and music, Yo gyakarta : Pustaka Sufi, 2002.

Kutha Ratna, Nyoman. Metodologi Penelitian. Kajian Budaya dan Ilmu Sosial Humaniora Pada Umumnya. Yogyakarta : Pustaka Pelajar, 2010.

Mangkey, Stanislaus; Jefry Herry Tamboto; Conny Renny Lasut; Orestis Soidi. Kebudayaan Minahasa: Kajian Etnolinguistik Tentang Konstruk Nilai Budaya Lokal Menghadapi Persaingan Global. Jurnal Interlingua vol. 4. April 2010:71-74.

Miles, Matthew B. \& A. Michael Huberman. Analisis Data Kualitatif. Terj. Tjetjep Rohendi Rohidi. Jakarta : Universitas Indonesia Press, 1992.

Miller, Hugh. History of Music (fourth editon). New York: TheBarnes \& Noble. Tanpa tahun terbit.

Parto, Suhardjo. Orang Orang Spanyol dan Portugis dalam $\mathrm{Bu}$ daya Budaya Musik di Nusantara ". Makalah yang disampaikan dalam International Symposium Cultural Studies Around The South West Pasific Region. Manado: Faculty of Letters, Sam Ratulangie University, February1995.

Pease, Ted. Jazz Composition: theory and practice. Boston, Massachusetts: Berklee Press, 2003

Robinson, Jenefer. Music and Meaning. USA : Cornell University Press, 1997.

Rumengan, Perry. Musik Vokal Etnik Minahasa Kontinuitas DanPerubahan Dalam Struktur Dan Fungsi ". Disertasi Universitas Gajah Mada, 2007. 
Musik Vocal Etnik

Minahasa. Teori, Gramatika, dan Estetika. Jakarta : Panitia Pelaksana Kongres Kebudayaan Minahasa, 200 9.

\section{Hubungan Fungsional :} Struktur Musikal Aspek Ekstramusikal Musik Vokal Etnik Minahasa. Yogyakarta : Program Pascasarjana ISI Yogyakarta, 2011.

Santosa. Komunikasi Seni Aplikasi Dalam Pertunjukan Gamelan.Surakarta : ISI Press, 2012.

Sema, Daniel. "Flamenco: Seni Bermain Gitar dari Andalucia" Jurnal Ilmiah Seni Musik Jurusan Musik Fakultas Seni Pertunjukan, Universitas Satya Wacana Vol.1 No.2, Juli 2009: 103112.

Slonimsky, Nicolas. Webster's New World Dictionary of Music (ed. Richard Kassel). New York: MacMillan. 1998.

Sylado, Remi. Nyanyian Kematian dalam Tradisi Sinkretisme di Minahasa dalam Suka Harjana, ed,. Seni Pertunjukan Indonesia. Surakarta: Masyarakat Seni Indonesia dan Yogyakarta : Yayasan Bentang Budaya, 1995.

Tim Penyusun Kamus Bahasa Indonesia. Kamus Pusat Bahasa. Jakarta: Pusat Bahasa, 2008

Warokka, Djerry. Kamus Bahasa Daerah Manado Minahasa. Jakarta: Alfa Indah, 2005.

Wenas, Noldy. Makaaruyen di Minahasa . UNIMA Manado : Skripsi S1 Prodi Sendratasik Jurus an Seni rupa dan kerajinan fakultas Bahasa dan seni UNIMA 2008.

Whitman, Brian A. Learning the Meaning of Music. (Submitted to the Program in Media Arts and Sciences, School of Architecture and Planning, in partial fulfillment of the requirements for the degree of Doctor of Philosophy at the Massachusetts Institute of Technology, June, 2005.

Yudkin, Jeremy. Understanding Music . New Jersey: Prentice Hall, Inc. 1999. 